\title{
Patient Care Outside of Office Visits
}

\author{
Melinda A. Chen, MD, MS ${ }^{7}$, James P. Hollenberg, $M D^{7}$, Walid Michelen, $M D^{2}$, \\ Janey C. Peterson, EdD, RN ${ }^{7}$, and Lawrence P. Casalino, MD, $P h D^{7}$
}

'Weill Cornell Medical College, New York, NY, USA; ${ }^{2}$ Generations+/Northern Manhattan Health Network, New York, NY, USA.

Authors reply:- We thank Dr. Schattner for his response to our article. We agree that, in addition to the time constraints placed on primary care physicians due to patient care activities outside of office visits (AOVs), physicians also face significant time constraints in providing comprehensive care to patients during office visits ${ }^{1,2}$. The proposed time-to-task ratio may be a useful way of studying time allocation to essential components of patient care both in and outside of office visits.

The time spent performing AOVs is separate but related to in-visit care time, both of which are major parts of the physician workday. Our study found that the majority of AOVs were "non-visit specific," meaning that they did not pertain to patients seen for an office visit on the study day. We found that general internists perceived that a substantial portion of these non-visit-specific AOVs substituted for office visits, with each performed in less than a quarter of the time that a visit required. If policies were realigned to encourage substitution of non-visit-based care encounters for visit-based care when

Published online December 8, 2010 appropriate, more time might be freed up for physicians to spend in fewer but longer office visits with the patients that require face-to-face care encounters.

Melinda A. Chen MD, MS, Weill Cornell Medical College, 1300 York Avenue, Box \#46, New York, NY, USA (e-mail: mec2015@med. cornell.edu).

\section{REFERENCES}

1. Ostbye T, Yarnall KS, Krause KM. Is there time for management of patients with chronic diseases in primary care? Ann Fam Med. 2005;3 (3):209-14

2. Yarnall KS, Pollak KI, Ostbye T, et al. Primary care: is there enough time for prevention? Am J Public Health. 2003;93(4):635-41.

J Gen Intern Med 26(3):235

DOI: $10.1007 / \mathrm{s} 11606-010-1590-8$

(C) Society of General Internal Medicine 2010 